\title{
Rotavirus Vaccine
}

National Cancer Institute

\section{Source}

National Cancer Institute. Rotavirus Vaccine. NCI Thesaurus. Code C96394.

A viral vaccine that prevents against rotavirus infection, the leading cause of severe acute gastroenteritis. 